Article

\title{
In Vitro Adventitious Regeneration of Artemisia annua L. Influencing Artemisinin Metabolism
}

\author{
Federica Blando (D), Francesca Rizzello, Miriana Durante ${ }^{(D}$, Angelo De Paolis* , Sofia Caretto *(D) \\ and Giovanni Mita (D)
}

Citation: Blando, F.; Rizzello, F.;

Durante, M.; De Paolis, A.; Caretto, S.; Mita, G. In Vitro Adventitious

Regeneration of Artemisia annua L. Influencing Artemisinin Metabolism. Horticulturae 2021, 7, 438. https:// doi.org/10.3390/horticulturae7110438

Institute of Sciences of Food Production (ISPA-CNR), 73100 Lecce, Italy; federica.blando@ispa.cnr.it (F.B.); rizzellofrancesca@libero.it (F.R.); miriana.durante@ispa.cnr.it (M.D.); giovanni.mita@ispa.cnr.it (G.M.)

* Correspondence: angelo.depaolis@ispa.cnr.it (A.D.P.); sofia.caretto@ispa.cnr.it (S.C.)

\begin{abstract}
Artemisia annua L. is a herbaceous plant belonging to the Asteraceae family, known for producing, although at low levels, the sesquiterpene lactone artemisinin (AN), which is highly effective against malaria. In this study, an in vitro regeneration process of $A$. annua L. using 'Artemis' progeny was established and the potential of tissue culture for inducing new variability in terms of AN metabolism of in vitro regenerated plants was investigated. Among the plant growth regulators tested, the cytokinin 6-benzyladenine (BA) at $4.4 \mu \mathrm{M}$ in combination with the auxin indole-butyric acid (IBA) at $0.35 \mu \mathrm{M}$ yielded the greatest frequency of shoot induction. The optimal multiplication medium contained BA at $0.9 \mu \mathrm{M}$ and naphthaleneacetic acid (NAA) at $0.05 \mu \mathrm{M}$. Regenerated plants (RPs), after transferring to the greenhouse and subsequently to the field, were analyzed during the growth cycle at different sampling times, showing a peak of AN content 20 days before blossom. Variability among different RPs and sampling times, in terms of AN and its precursors dihydroartemisinic acid (DHAA) and artemisinic acid (AA) was observed. This suggests that adventitious shoot induction could provide a useful strategy to induce variability influencing artemisinin metabolism as a consequence of in vitro manipulation.
\end{abstract}

Keywords: Artemisia annua; organogenesis; in vitro regeneration; artemisinin metabolism; micropropagation

Academic Editor: Sergio

Ruffo Roberto

Received: 16 September 2021

Accepted: 26 October 2021

Published: 28 October 2021

Publisher's Note: MDPI stays neutral with regard to jurisdictional claims in published maps and institutional affiliations.

\section{Introduction}

Artemisia annua L. is a herbaceous plant belonging to the Asteraceae family, native to China and now widely growing in India, Argentina, USA and many other European countries. A. annua plants biosynthesize the compound artemisinin (AN) in glandular trichomes of leaves and inflorescences. AN is a sesquiterpene lactone endoperoxide active in the treatment of malaria, caused by the protozoan microbe Plasmodium sp. [1]. Due to the increasing resistance of Plasmodium strains to the most commonly used synthetic antimalarial compounds, the World Health Organization (WHO) has recommended the shift towards AN-based combination treatments (ACTs) [2].

The AN content in A. annua plants is quite low being $0.1-1 \%$ dry weight (DW); therefore, $\mathrm{AN}$ is in very short supply on the international market. AN content varies with plant age, photoperiod and nutrients but mainly depends on the genotype. A. annua hybrid 'Artemis' with up to $1 \%$ (DW) AN content was selected by traditional breeding [3].

Efforts aimed at improving AN production in A. annua plants have been made in the last twenty years by different biotechnological approaches, such as metabolic engineering using transgenic plants $[4,5]$. In addition, the transcriptional regulation of sesquiterpene pathways [6], and the selection of genotypes with high-artemisinin content and valuable agronomic characteristics $[7,8]$ were also investigated. In vitro production of AN was also explored and could be achieved in plant cells or hairy root cultures and enhanced by the application of abiotic and/or biotic elicitors [9-11]. Metabolic engineering of microorganisms 
and synthetic biology have been successfully combined to produce semi-synthetic AN [12]. Nevertheless, it was reported that pure AN was less effective than intact dried leaves in treating malaria [13], making it desirable to keep exploring strategies for enhancing the AN supply from plant extracts. Ferreira et al. [14], by reporting on the seasonal and differential sesquiterpene accumulation in plants of three high-AN cultivars, including 'Artemis', suggested that selection based on both AN and its precursor dihydroartemisinic acid (DHAA) may increase AN in A. annua plants.

Plant tissue cultures have shown a potential for plant improvement since their application can induce possible genetic variability in regenerated plants (RPs). The exposure of plant cells and tissues to stressful in vitro conditions can be a source of mutations and uncovering natural variability, which can be exploited for identifying novel useful variants $[15,16]$. In this regard, the regeneration of $A$. annua by organogenesis was achieved in different genotypes [7,17-21].

In this study, we investigated the effects of different plant growth regulators on the regeneration process in A. annua L. using 'Artemis' progeny and evaluated the potential of tissue culture to induce new variability in terms of AN metabolism of in vitro RPs.

\section{Materials and Methods}

\subsection{Plant Material}

A. annua seeds were obtained from open-pollinated 'Artemis' plants (Mediplant, Conthey, Switzerland) cultivated at Consiglio per la Ricerca e Sperimentazione in Agricoltura (CREA), Lecce, Italy.

\subsection{Chemicals}

MS [22] medium, agar (Plant agar), and plant growth regulators thidiazuron (TDZ), 2,4-dichlorophenoxyacetic acid (2,4-D), indole-butyric acid (IBA), 6-benzyladenine (BA), and $\alpha$-naphthaleneacetic acid (NAA) were purchased from Duchefa Biochemie (Haarlem, Netherlands). Ultrapure water, supplied by J.T. Backer (Avantor, Milano, Italy), was used to prepare culture media. HPLC-grade methanol and acetonitrile were purchased from Fluka SA (Buchs, Switzerland). AN standard was obtained from Sigma (St. Louis, MO, USA). DHAA and artemisinic acid (AA) standards were kindly provided by P.S. Covello (National Research Council of Canada, Saskatoon, SK, Canada).

\subsection{Culture Media and Conditions for the Regeneration Induction}

A. annua seeds were surface-sterilized by several steps: (i) extensive washing under running tap water, (ii) submerging for $5 \mathrm{~min}$ in $80 \%(v / v)$ ethanol, (iii) submerging for $20 \mathrm{~min}$ in $30 \%(v / v)$ commercial bleach, and (iv) 3 or more rinses in sterile distilled water.

Sterilized seeds were transferred to MS/2 medium (hormone-free half-strength MS) in Vitrobox (Duchefa Biochemie, Haarlem, Netherlands) and after 15 days, leaf explants were excised from random chosen developed seedlings. The explants (3-5 mm diameter leaf discs) were immediately placed onto a regeneration medium (RM) in a sterile Petri dish (Corning Inc., $5.5 \mathrm{~cm}$ diameter) with five explants per dish (10 dishes totally) and kept in the dark for 20 days in the growth room. From the same seedlings, leaf samples were taken for AN analysis. The RM included MS salts and vitamins enriched with a sterile solution of plant growth regulators, added after autoclaving, RM1: BA $4.4 \mu \mathrm{M}$ and IBA $0.35 \mu \mathrm{M}$; RM2: TDZ $\mu \mathrm{M}$ and IBA $0.35 \mu \mathrm{M}$. Multiplication medium (MM) designed for microshoot proliferation, consisted of MS medium enriched with BA $0.9 \mu \mathrm{M}$ and NAA $0.5 \mu \mathrm{M}$, added before autoclaving. Sucrose $(3 \% w / v)$ was added to all media. The $\mathrm{pH}$ of all the media was adjusted to 5.7 with $1 \mathrm{M} \mathrm{KOH}$ before the addition of $0.75 \%(w / v)$ agar. The media were autoclaved at $121{ }^{\circ} \mathrm{C}$ for $20 \mathrm{~min}$. All in vitro cultures were maintained in a growth room at $25 \pm 2{ }^{\circ} \mathrm{C}$, in the dark or under a light intensity of $120 \mu \mathrm{mol} \mathrm{m}^{-2} \mathrm{~s}^{-1}$ provided by Philips TLD/83 white fluorescent tubes, positioned $40 \mathrm{~cm}$ above the level of the cultures, with a $16 \mathrm{~h}$ photoperiod. 
After 20 days the explants were checked for morphogenetic response (regeneration process) under the stereomicroscope. The frequency of callus formation (number of explants forming callus/total number of explants) and shoot induction (number of explants forming shoots/total number of explants) were calculated. Additionally, the number of regenerated shoots per explants was counted.

\subsection{Shoot Elongation, Multiplication and Root Development}

Explants with adventitious buds, induced on the surface of 'mother' leaf explants, were placed on MS/2 for two weeks to elongate shoots, under the light and in $5 \mathrm{~cm}$ diameter Petri dishes, one explant/dish. Subsequently, elongated shoots were excised and transferred to MM in order to obtain clones for each regenerated shoot by means of micropropagation process. The cultures were maintained in the light and subcultured every 20 days. Shoots from the multiplication stage were also induced to root on MS/ 2 for two weeks.

\subsection{Acclimatization and Field Cultivation}

Rooted plants were gently washed in tap water to remove agar from the roots and transplanted to small clay pots containing a mixture of sterilized soil and peat (1:1). Each pot was covered by a glass beaker to maintain high humidity for nearly two weeks. Subsequently, the plantlets were gradually hardened in greenhouse over two more weeks, before being transferred to the field.

\subsection{Artemisinin, Dihydroartemisinic Acid and Artemisinic Acid Extraction and Analysis}

Freeze-dried leaf samples $(50 \mathrm{mg}$ ) were extracted with $5 \mathrm{~mL}$ n-hexane for $16 \mathrm{~h}$ under magnetic stirring. The mixture was centrifuged at $4000 \times g$ for $10 \mathrm{~min}$, and the supernatant was removed and placed in new tubes. The pellet was extracted again with $2 \mathrm{~mL} n$-hexane for $2 \mathrm{~h}$ on a rotary shaker; then, after being centrifuged as above, this second supernatant was added to the first, dried under vacuum. Extracts were stored at $-20^{\circ} \mathrm{C}$ until HPLC analysis. For AN determination, the $\mathrm{Q}_{260}$ derivative was analysed by HPLC according to Smith et al. [23] and as previously reported [9]. Samples were resuspended in $1 \mathrm{~mL}$ absolute ethanol and derivatized by addition of $200 \mu \mathrm{L} 60 \mathrm{mM} \mathrm{NaOH}$, then briefly vortexed and incubated in an oven at $45^{\circ} \mathrm{C}$ for $30 \mathrm{~min}$. After cooling to room temperature, samples were acidified with $200 \mu \mathrm{L}$ acetic acid (62.5 mM final concentration), briefly vortexed and centrifuged for $1 \mathrm{~min}$ in a microcentrifuge at maximum speed. AN standard derivatized as described above and properly diluted, was used to prepare standard curves for AN quantification. HPLC analyses were carried out using an Agilent 1100 Series (Agilent Technologies, Santa Clara, CA, USA) HPLC system equipped with pre-column guard, Ultrasphere ODS $(0.46 \times 4.5 \mathrm{~cm}, 5 \mu \mathrm{m}$ particle size; Beckmann, Fullerton, CA, USA) and a C18 Ultrasphere ODS column $(0.46 \times 25 \mathrm{~cm}, 5 \mu \mathrm{m}$ particle size; Beckmann). The mobile phase was methanol: sodium phosphate buffer, $\mathrm{pH} 7.0(55: 45 \mathrm{v} / \mathrm{v})$ at $1 \mathrm{~mL} \mathrm{~min}^{-1}$ constant flow rate, $35^{\circ} \mathrm{C}$ column temperature and $260 \mathrm{~nm}$ wavelength for detection. The injection volume was $20 \mu \mathrm{L}$. Putative AN peaks were confirmed by reanalyzing a sample co-injected with standard AN and by comparing spectra of the standard and putative AN peaks.

Analysis of DHAA and AA were performed using an HPLC system pre-column and column as above described. The mobile phase was acetonitrile and $\mathrm{H}_{2} \mathrm{O}$ (acidified with phosphoric acid $1 \%)$ in the ratio $8: 2(60: 40 \mathrm{v} / \mathrm{v}) 1 \mathrm{~mL} \mathrm{~min}^{-1}$ constant flow rate, $25{ }^{\circ} \mathrm{C}$ column temperature and $260 \mathrm{~nm}$ wavelength for detection. The injection volume was $20 \mu \mathrm{L}$. The identification of DHAA and AA was confirmed by spectrophotometric analysis of standards, solubilized in ethanol.

\subsection{Statistical Analysis}

The design of all the experiments was a complete randomized block, and each experiment consisted of five explants per dish and ten replicate culture dishes per plant growth regulator treatment. All experiments were repeated twice. Statistical analysis was based 
on one-way analysis of variance (ANOVA). Holm-Sidak post hoc method was applied to establish significant differences between means $(p<0.05)$. Data are mean \pm standard deviation (SD). SigmaPlot Ver 12.0 (Sistat Software, Inc., San Jose, CA, USA) was used.

\section{Results}

3.1. Effects of Plant Growth Regulators on the Induction of the Regeneration Process

Leaf explants of $A$. annua $\mathrm{L}$. from random chosen in vitro seedlings were cultured on RM containing different combinations of plant growth regulators selected after preliminary experiments (data not shown). After three weeks in dark conditions, on RM1 (BA $4.4 \mu \mathrm{M}$ and IBA $0.35 \mu \mathrm{M})$, most cultured explants showed multiple shoot bud induction and regeneration (Table 1). Regeneration was in some cases very conspicuous (Figure 1a). On the contrary, explants with TDZ-added medium (RM2) enlarged and swelled. Only a few regenerated structures were visible under microscopic observation, but they did not proceed to development (Figure 1b, Table 1). When explants from RM1 were transferred to MS / 2 in the light, in a few days the regenerated structures became more evident and greener, producing fully developed shoots (Figure 1c).

Table 1. Effects of plant growth regulators on the morphogenetic response of leaf disc explants of Artemisia annua. Values are expressed as percentages (\%) or means $\pm S D$ ( $n=50$, two independent experiments).

\begin{tabular}{cccc}
\hline Medium & Plant Growth Regulators $(\mu \mathrm{M})$ & Shoot Producing Explants $(\%)$ & Regenerated Shoots/Explant $($ Mean) \\
\hline RM1 & BA 4.4 + IBA 0.35 & 91.8 & $4.9 \pm 2.6$ \\
RM2 & TDZ 4.5 + IBA 0.35 & $4^{1}$ & 0 \\
\hline
\end{tabular}

${ }^{1}$ Regenerated structures were rarely visible to microscopic observation, but they did not proceed to development.

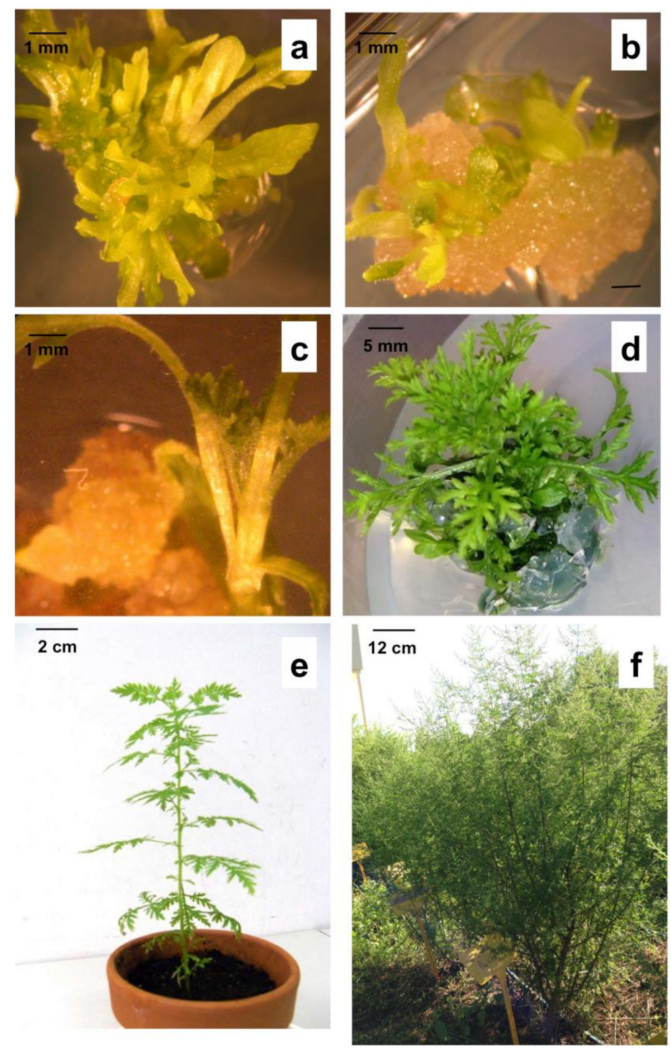

Figure 1. Regeneration process in Artemisia annua L. Shoot regeneration from leaf discs on RM1 (a) and RM2 (b) after 20 days in dark conditions. (c) Shoot elongation from RM1 regeneration after light exposure. (d) Microshoots on multiplication medium. (e) Regenerated plants (RPs) acclimatized in the greenhouse. (f) RPs growing in the field. 


\subsection{Micropropagation of Regenerants, Root Development and Acclimatization}

Fifty fully developed shoots, excised from the regenerating explants, were used as secondary explants for multiplication (micropropagation). A reasonable proliferation rate (1:3) and development of vigorous shoots (Figure 1d) were achieved on the medium containing BA $0.9 \mu \mathrm{M}$ and NAA $0.05 \mu \mathrm{M}$. Higher levels of BA concentrations (2.2-4.4-6.6 $\mu \mathrm{M})$, even though they induced higher axillary bud proliferation, led to the production of shoots suffering from vitrification (data not shown). Finally, the medium containing BA $0.9 \mu \mathrm{M}$ was selected as the optimal MM; a 15-20 day-subculture period was required, in agreement with previous reports $[24,25]$.

Elongated and developed shoots obtained after shoot multiplication steps, were placed on MS/ 2 without hormones. Root-inducing growth regulators were not used, as regenerated shoots easily produced roots in half-strength MS medium without hormones within two weeks, exploiting the natural endogenous growth regulator levels. When roots were developed enough (plantlets $4-5 \mathrm{~cm}$ tall, with roots $1-2 \mathrm{~cm}$ long), rooted microplants were gently washed removing agarized medium and transplanted into small clay pots for acclimatization in a greenhouse (Figure 1e). After two weeks of acclimatization in a greenhouse, surviving RPs reached the optimal development to be transferred to an open field, where they showed a regular vegetative development and flowering (Figure 1f).

\subsection{Evaluation of Artemisinin and Precursors in Seedlings and RPS}

AN content was analysed in A. аппи samples from seedlings and in vitro grown RPs. Figure 2 shows the HPLC chromatograms of A. annua extracts (Figure 2a) and spectra of AN standard in comparison with the putative AN peaks from plant extracts (Figure $2 b$ ).
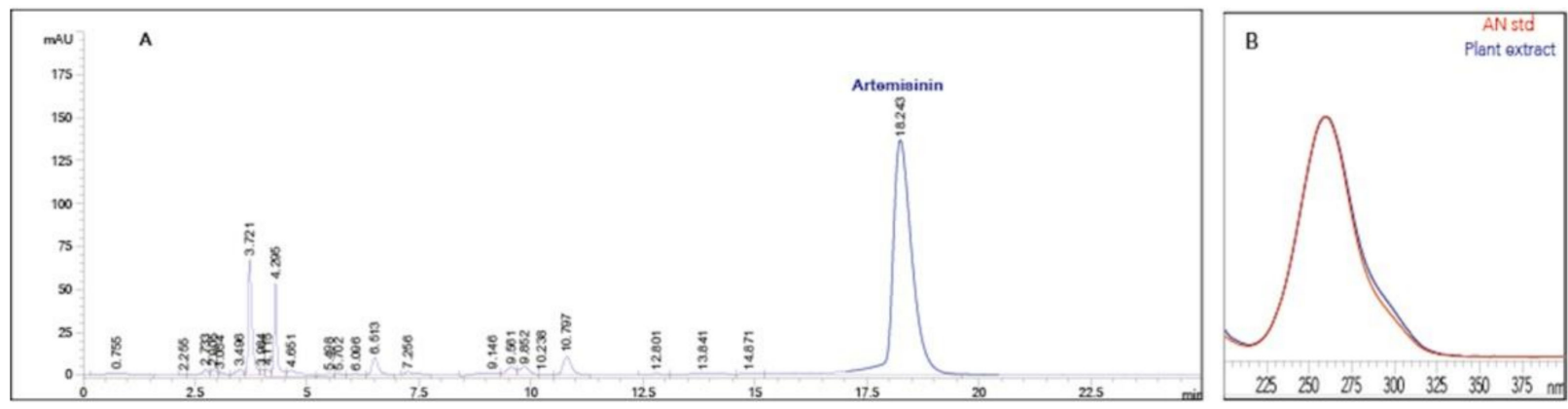

Figure 2. Artemisinin analysis of Artemisia annua regenerated plants (RPs). HPLC chromatogram of plant extracts. The putative artemisinin peak (A) was confirmed by comparing spectra of the standard artemisinin with the putative artemisinin peak (B).

When the AN content of five in vitro grown RPs was measured, variability was observed; particularly, the AN of RP5 was significantly higher $(\mathrm{F}=205.88, p=0.005)$ compared to the average AN value detected in the starting seedlings (Figure 3 ). When AN content was analyzed in leaf samples of RPs acclimatized and grown in pots in the greenhouse, an increase was found compared to the AN content of RPs grown in vitro. Interestingly, the AN content of RP5 was 2.1 times higher than the average AN content of the other RPs, being 7.8 times higher than seedlings (Figure 3).

After two weeks in the greenhouse, RPs were transferred to the field and evaluated for AN, DHAA and AA contents during the growth cycle at different sampling times (Figure 4). A significant peak of AN content was observed twenty days before blossom in all the analysed RPs (Figure 4A). RP2, RP4 and RP5 showed a significant peak of DHAA twenty days before blossom while RP3 showed a significant DHAA peak at an earlier time (Figure 4B). Variability among different RPs was also observed for the precursor AA, in terms of metabolite levels and sampling times (Figure 4C). 


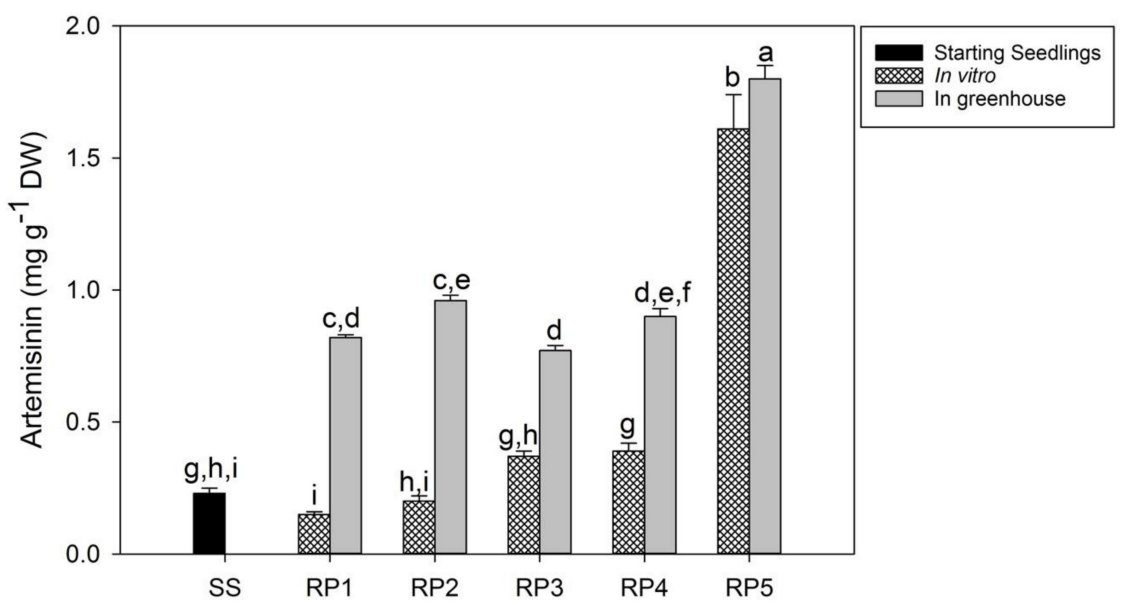

Figure 3. Artemisinin analysis of Artemisia annua in seedlings and regenerated plants (RPs). Data are expressed as $\mathrm{mg} \mathrm{g}^{-1}$ (DW) and are means \pm standard deviation of two independent replicates $(n=2)$. Data were submitted to one-way analysis of variance (ANOVA). Differences among groups were detected using multiple comparison procedures (Tukey test) and indicated with different letters.
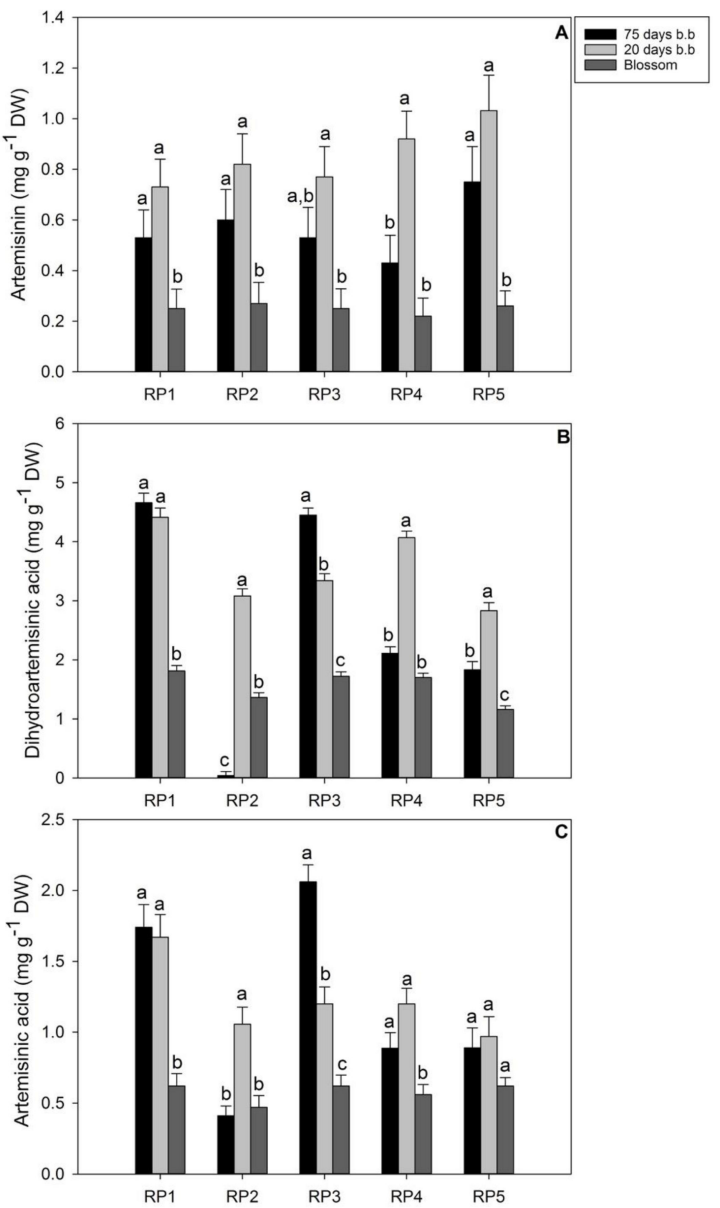

Figure 4. Artemisinin (A), Dihydroartemisinic acid (B) and Artemisinic acid (C) content in Artemisia annua regenerated plants (RPs) at different sampling times (b.b. = before blossom). Data are expressed as $\mathrm{mg} \mathrm{g}^{-1} \mathrm{DW}$ and are means \pm standard deviation of two independent replicates $(n=2)$. Data were submitted to one-way analysis of variance (ANOVA). Differences in the same groups were detected using multiple comparison procedures (Tukey test) and indicated with different letters. 


\section{Discussion}

In this study, we established an in vitro regeneration process of $A$. annua $\mathrm{L}$. using 'Artemis' progeny and investigated the potential of tissue cultures to obtain enhanced variability in terms of AN metabolism of in vitro regenerated plants.

Previously, several authors have investigated the regeneration of A. annua by organogenesis in different cultivars [17-21]. In particular, in the first report by Vergauwe et al. [17], regeneration was induced through callus formation at a low rate; later attempts considered leaf explants directly induced to regenerate without callus formation, obtaining considerable regeneration frequencies in different $A$. annua strains from China and Thailand [18-20]. Differently from previous reports, in the present study, we used 'Artemis' open-pollinated plants as the source of leaf discs, which were used as primary explants to induce shoot regeneration. These explant sources usually take advantage of the wounding effect as an inducing cell proliferation factor, together with dark conditions. Preliminary experiments in our laboratory showed that the concentration of $4.4 \mu \mathrm{M}$ BA was the best performing when combined with the auxin IBA $0.35 \mu \mathrm{M}$, compared to other hormone combinations (data not shown). In addition, we applied a TDZ treatment, known to induce multiple shoot regeneration in A. annua from Thailand [20], at the same $\mu$ molar concentration as BA. Surprisingly, in our experiments, the effect of TDZ on the A. annua explants was different from that previously reported. Indeed, no efficient regeneration was observed in repeated experiments using TDZ as cytokinin, while good results were obtained using BA (Table 1, Figure 1a,b). Since regeneration is a genotype-dependent process, it can be hypothesized that the observed different response to the synthetic cytokinin TDZ was due to the different genotype. Other studies reported differing results when the same culture conditions were applied to different $A$. annua cultivars [18,19].

In vitro rooting of our regenerated shoots confirmed previous observations on the efficacy of a half-strength MS medium on the in vitro rooting of $A$. annua, indicating the involvement of endogenous plant growth regulators $[25,26]$.

As for acclimatization to the greenhouse conditions, this stage was revealed to be particularly critical for the successful establishment of field plants. On the other hand, it is known that microplants have a leaf structure (characterized by reduced leaf epicuticular wax, poor stomatal function and high stomatal density) that determines an excessive transpiration, causing water deficit after transplanting from in vitro culture to the greenhouse [27].

Plant tissue culture has shown a potential for plant improvement since it can induce genetic variability detectable in RPs. The exposure to in vitro conditions can uncover natural variability, which can be exploited for identifying novel useful variants $[15,16]$. In a previous work, while screening sunflower cell suspension cultures, two cell lines were identified and characterized for their differing capability to biosynthesize vitamin E [28]. In this study, when AN was evaluated in RPs, grown in vitro and in the greenhouse, variability was observed. The enhanced AN content detected in RPs grown in the greenhouse can be due to the changed growth conditions promoting the development of plant tissue differentiation. Nevertheless, a low AN content in A. annua leaves of in vitro grown plants had already been observed [29]. Furthermore, field plants made it possible to analyze AN and precursors during the growth cycle, revealing variability both in terms of metabolite contents and sampling times. Interestingly, this was evident for DHAA, which is known to be the immediate precursor of AN [30]. The observed variations of AN metabolites were likely due to the in vitro culture conditions, which might have affected the AN biosynthetic pathway. Since in vitro tissue cultures have been recently associated to a wide range of epigenetic variations affecting gene expression [31,32], it can be hypothesized that the in vitro regeneration process of $A$. annua plants could have influenced the expression of some biosynthetic genes or, more generally, the regulation of AN metabolism inducing metabolite changes. On the other hand, the genetically stable variation induced by in vitro culture conditions was usefully exploited for crop improvement, in a similar manner of that induced by chemical and physical mutagens [33,34]. As for AN, it was reported that 
the highest accumulation in $A$. annua leaves was reached before plant blossom $[3,35]$ or at blossom [1], and the highest AN content was detected 20 days before blossom in all RPs confirmed in these reports.

In conclusion, plant tissue cultures have a great potential for improving variability to be exploited for identifying plants with high contents of useful metabolites. Adventitious shoot induction in A. annua developed in this study can provide a useful strategy to induce variability influencing $\mathrm{AN}$ metabolism as a consequence of in vitro manipulation.

Author Contributions: Conceptualization, F.B. and G.M.; methodology, F.B. and F.R.; validation, F.B., F.R., M.D. and S.C.; formal analysis, F.B., F.R. and M.D.; resources, G.M.; data curation, A.D.P., F.B., M.D. and S.C.; writing — original draft preparation, F.B. and S.C.; writing-review and editing, A.D.P., F.B. and S.C.; supervision, F.B.; funding acquisition, G.M. and S.C. All authors have read and agreed to the published version of the manuscript.

Funding: This research was funded by Regione Puglia, Italy, Progetto Strategico PS070.

Institutional Review Board Statement: Not applicable.

Informed Consent Statement: Not applicable.

Acknowledgments: The authors would like to thank Giovanni Colella for his valuable technical assistance, P. Greco, (CREA, Lecce) for field cultivating A. annua plants, Rita Accogli for greenhouse facilities and Simona Bavaro for the critical reading of the manuscript.

Conflicts of Interest: The authors declare no conflict of interest.

\section{References}

1. Ferreira, J.F.S.; Simon, J.E.; Janick, J. Artemisia annua: Botany, Horticulture, Pharmacology. Hortic. Rev. 1996, 19, 319-371. [CrossRef]

2. WHO. Antimalarial Drug Combination Therapy: Report of a WHO Technical Consultation; WHO: Geneva, Switzerland, 2001.

3. Delabays, N.; Simonnet, X.; Gaudin, M. The genetics of artemisinin content in Artemisia annua L. and the breeding of high yielding cultivars. Curr. Med. Chem. 2001, 8, 1795-1801. [CrossRef] [PubMed]

4. Tang, K.; Shen, Q.; Yan, T.; Fu, X. Transgenic approach to increase artemisinin content in Artemisia annua L. Plant Cell Rep. 2014, 33, 605-615. [CrossRef]

5. Di Sansebastiano, G.P.; Rizzello, F.; Durante, M.; Caretto, S.; Nisi, R.; De Paolis, A.; Faraco, M.; Montefusco, A.; Piro, G.; Mita, G. Subcellular compartmentalization in protoplasts from Artemisia annua cell cultures: Engineering attempts using a modified SNARE protein. J. Biotechnol. 2015, 202, 146-152. [CrossRef] [PubMed]

6. De Paolis, A.; Caretto, S.; Quarta, A.; Di Sansebastiano, G.P.; Sbrocca, I.; Mita, G.; Frugis, G. Genome-Wide Identification of WRKY Genes in Artemisia annua: Characterization of a Putative Ortholog of AtWRKY40. Plants 2020, 9, 1669. [CrossRef] [PubMed]

7. Wetzstein, H.Y.; Porter, J.A.; Janick, J.; Ferreira, J.F.S.; Mutui, T.M. Selection and Clonal Propagation of High Artemisinin Genotypes of Artemisia annua. Front. Plant Sci. 2018, 9, 358. [CrossRef] [PubMed]

8. Wetzstein, H.Y.; Janick, J.; Ferreira, J.F.S. Germplasm Release of Four High-artemisinin Clones of Artemisia annua L. Hortscience 2019, 54, 2081-2082. [CrossRef]

9. Caretto, S.; Quarta, A.; Durante, M.; Nisi, R.; De Paolis, A.; Blando, F.; Mita, G. Methyl jasmonate and miconazole differently affect arteminisin production and gene expression in Artemisia annua suspension cultures. Plant Biol. 2011, 13, 51-58. [CrossRef]

10. Durante, M.; Caretto, S.; Quarta, A.; De Paolis, A.; Nisi, R.; Mita, G. beta-Cyclodextrins enhance artemisinin production in Artemisia annua suspension cell cultures. Appl. Microbiol. Biotechnol. 2011, 90, 1905-1913. [CrossRef] [PubMed]

11. Ahlawat, S.; Saxena, P.; Alam, P.; Wajid, S.; Abdin, M.Z. Modulation of artemisinin biosynthesis by elicitors, inhibitor, and precursor in hairy root cultures of Artemisia annua L. J. Plant Interact. 2014, 9, 811-824. [CrossRef]

12. Paddon, C.J.; Keasling, J.D. Semi-synthetic artemisinin: A model for the use of synthetic biology in pharmaceutical development. Nat. Rev. Microbiol. 2014, 12, 355-367. [CrossRef]

13. Weathers, P.J.; Elfawal, M.A.; Towler, M.J.; Acquaah-Mensah, G.K.; Rich, S.M. Pharmacokinetics of artemisinin delivered by oral consumption of Artemisia annua dried leaves in healthy vs. Plasmodium chabaudi-infected mice. J. Ethnopharmacol. 2014, 153, 732-736. [CrossRef] [PubMed]

14. Ferreira, J.F.S.; Benedito, V.A.; Sandhu, D.; Marchese, J.A.; Liu, S. Seasonal and Differential Sesquiterpene Accumulation in Artemisia annua Suggest Selection Based on Both Artemisinin and Dihydroartemisinic Acid may Increase Artemisinin in planta. Front. Plant Sci. 2018, 9. [CrossRef] [PubMed]

15. Larkin, P.J.; Scowcroft, W.R. Somaclonal variation-A novel source of variability from cell cultures for plant improvement. Theor. Appl. Genet. 1981, 60, 197-214. [CrossRef]

16. Krishna, H.; Alizadeh, M.; Singh, D.; Singh, U.; Chauhan, N.; Eftekhari, M.; Sadh, R.K. Somaclonal variations and their applications in horticultural crops improvement. 3 Biotech 2016, 6, 54. [CrossRef] [PubMed] 
17. Vergauwe, A.; Cammaert, R.; Vandenberghe, D.; Genetello, C.; Inze, D.; Van Montagu, M.; Van den Eeckhout, E. Agrobacterium tumefaciens-mediated transformation of Artemisia annua L. and regeneration of transgenic plants. Plant Cell Rep. 1996, 15, 929-933. [CrossRef]

18. Chen, D.; Ye, H.; Li, G. Expression of a chimeric farnesyl diphosphate synthase gene in Artemisia annua L. transgenic plants via Agrobacterium tumefaciens-mediated transformation. Plant Sci. 2000, 155, 179-185. [CrossRef]

19. Han, J.L.; Wang, H.; Ye, H.C.; Liu, Y.; Li, Z.Q.; Zhang, Y.; Zhang, Y.S.; Yan, F.; Li, G.F. High efficiency of genetic transformation and regeneration of Artemisia annua L. via Agrobacterium tumefaciens-mediated procedure. Plant Sci. 2005, 168, 73-80. [CrossRef]

20. Lualon, W.; De-Eknamkul, W.; Tanaka, H.; Shoyama, Y.; Putalun, W. Artemisinin production by shoot regeneration of Artemisia annua L. using thidiazuron. Z. Naturforsch. C J. Biosci. 2008, 63, 96-100. [CrossRef] [PubMed]

21. Lei, C.Y.; Wang, H.; Liu, B.Y.; Ye, H.C. Effects of silver nitrate on shoot regeneration of Artemisia annua L. Plant Biotechnol. 2014, 31, 71-75. [CrossRef]

22. Murashige, T.; Skoog, F. A revised medium for rapid growth and bioassays with tobacco tissue cultures. Physiol. Plant 1962, 51, 473-497. [CrossRef]

23. Smith, T.C.; Weathers, P.J.; Cheetham, R.D. Effects of gibberellic acid on hairy root cultures of Artemisia annua: Growth and artemisinin production. Vitr. Cell. Dev. Biol.-Plant 1997, 33, 75-79. [CrossRef]

24. Liu, C.-Z.; Guo, C.; Wang, Y.; Ouyang, F. Factors influencing artemisinin production from shoot cultures of Artemisia annua L. World J. Microbiol. Biotechnol. 2003, 19, 535-538. [CrossRef]

25. Almaarri, K.; Xie, D.Y. In vitro direct organogenesis and micropropagation of Artemisia annua. J. Biotechnol. Veg. 2010, 26, 327-337.

26. Hailu, T.; Abera, B.; Mariam, G. In vitro Mass Propagation of Artemisia (Artemisia annua L.) cv: Anamed. Plant Tissue Cult. Biotechnol. 2014, 23, 165-176. [CrossRef]

27. Preece, J.E.; Sutter, E.G. Acclimatization of micropropagated plants to the greenhouse and field. In Micropropagation: Technology and Application; Debergh, P.C., Zimmerman, R.H., Eds.; Springer: Dordrecht, The Netherlands, 1991; pp. 71-93. [CrossRef]

28. Caretto, S.; Paradiso, A.; D'Amico, L.; De Gara, L. Ascorbate and glutathione metabolism in two sunflower cell lines of differing $\alpha$-tocopherol biosynthetic capability. Plant Physiol. Biochem. 2002, 40, 509-513. [CrossRef]

29. Covello, P.S.; Teoh, K.H.; Polichuk, D.R.; Reed, D.W.; Nowak, G. Functional genomics and the biosynthesis of artemisinin. Phytochemistry 2007, 68, 1864-1871. [CrossRef]

30. Teoh, K.H.; Polichuk, D.R.; Reed, D.W.; Covello, P.S. Molecular cloning of an aldehyde dehydrogenase implicated in artemisinin biosynthesis in Artemisia annua. Botany 2009, 87, 635-642. [CrossRef]

31. Us-Camas, R.Y.; Rivera-Solís, G.; Duarte-Aké, F.; De-la-Peña, C. In vitro culture: An epigenetic challenge for plants. Plant Cell Tissue Organ Cult. (PCTOC) 2014, 118, 187-201. [CrossRef]

32. Sanchez-Muñoz, R.; Moyano, E.; Khojasteh, A.; Bonfill, M.; Cusido, R.M.; Palazon, J. Genomic methylation in plant cell cultures: A barrier to the development of commercial long-term biofactories. Eng. Life Sci. 2019, 19, 872-879. [CrossRef] [PubMed]

33. Mohan Jain, S. Tissue culture-derived variation in crop improvement. Euphytica 2001, 118, 153-166. [CrossRef]

34. Khan, S.A.; Rahman, L.U.; Shanker, K.; Singh, M. Agrobacterium tumefaciens-mediated transgenic plant and somaclone production through direct and indirect regeneration from leaves in Stevia rebaudiana with their glycoside profile. Protoplasma 2014, 251, 661-670. [CrossRef] [PubMed]

35. Woerdenbag, H.J.; Lüers, J.F.J.; van Uden, W.; Pras, N.; Malingré, T.M.; Alfermann, A.W. Production of the new antimalarial drug artemisinin in shoot cultures of Artemisia annua L. Plant Cell Tissue Organ Cult. 1993, 32, 247-257. [CrossRef] 